\title{
CONHECENDO ALGUNS MODELOS MENTAIS INFANTIS SOBRE FILARIOSE LINFÁTICA
}

\author{
Exploring some mental models of children \\ about Bancroftian filariasis
}

\author{
Micheline Barbosa da Motta ${ }^{1}$ \\ Francimar Martins Teixeira ${ }^{2}$
}

Resumo: A Filariose linfática é uma parasitose endêmica em Pernambuco desde 1918, com focos persistentes e em expansão na Região Metropolitana do Recife, tornando-se um desafio premente a ser encarado tanto pelas autoridades de saúde pública, como pela população e escolas de áreas de risco. Como subsídio para o planejamento de estratégias pedagógicas que estimulem os alunos a vivenciarem medidas preventivas para controle da doença, identificamos modelos mentais de cinqüenta alunos (nove-dez anos), residentes em áreas endêmicas da região metropolitana. Os resultados indicaram que as crianças: (a) acreditam que a filariose é evitável, tratável, causada por fator externo, e que o cumprimento das recomendações médicas é fundamental para o sucesso do tratamento; (b) têm dificuldades em identificar os sintomas e as etapas do processo de adoecimento; (c) apóiam seus modelos no que podem observar, o que possibilita a estruturação de ações pedagógicas que simulem, na escola, situações reais vividas pelas crianças em sua comunidade.

Palavras-chave: Filariose linfática. Elefantíase. Educação em saúde. Modelos mentais.

\begin{abstract}
Bancroftian filariasis has been an endemic parasite in Pernambuco since 1918 expanding into the metropolitan region of Recife, and becoming a permanent challenge to be faced by the public health authorities as well as by the population and schools in the risk areas. As support in creating pedagogic strategies that stimulate pupils to put into practice preventative measures against the disease, we identified the mental models of 50 pupils aged from 9 to 10, living at endemic areas of the Recife Metropolitan Region. The results indicated that the children: (a) believe that the filariasis can be avoided and treated, that it is caused by external factors and that the observance of medical recommendations is fundamental to the success of the treatment; (b) have difficulties in identifying the symptoms and phases of the disease; (c) they based their models on features they can see. This makes it possible to build pedagogical activities that simulate, in school, real situations lived by the children in its community.
\end{abstract}

Key words: Bancroftian filariasis. Elephantiasis. Health education. Mental models

\footnotetext{
${ }^{1}$ Mestre em Educação pela UFPE; professora assistente, Departamento de Métodos e Técnicas de Ensino, Universidade Federal de Pernambuco (UFPE). Recife, PE. <biomotta@yahoo.com.br>

${ }^{2}$ Doutora pela University of Bristol (UK); professora adjunta, Programa de Pós-Graduação em Educação, Departamento de Métodos e Técnicas de Ensino, Universidade Federal de Pernambuco (UFPE). Recife, PE. $<$ fmtm@terra.com.br>
}

${ }^{1}$ UfPE, Centro de Educação, Departamento de Métodos e Técnicas de Ensino Rua Acadêmico Hélio Ramos s/n, sala 111 Cidade Universitária - Recife, PE $50.670-920$ 


\section{Filariose linfática: uma questão de saúde pública}

Existem parasitoses que causam muitos problemas de ordem física (retardamento do crescimento corpóreo, desordem mental, ataques epileptiformes, assim como redução da capacidade de aprendizagem) enquanto outras, além dos problemas de ordem física podem provocar também danos de dimensão social, como a filariose linfática bancroftiana. ${ }^{3}$ Esta parasitose leva os doentes à segregação social, pelas deformidades no corpo (pernas, braços, escroto, vulva ou mama), muitas vezes irreversíveis em estágio avançado (BRASIL, 2000). Causada pelo verme Wuchereria bancrofti (filária), que é transmitido ao homem por meio da picada do Culex quinquefasciatus (muriçoca), leva o parasitado a uma crescente debilidade do sistema linfático, permitindo, inicialmente, um inchaço mole dos membros e, posteriormente, seu endurecimento, caracterizando a cronicidade da doença com uma deformidade permanente, conhecida como elefantíase (REY, 2001; ALBUQUERQUE, 1993). Vale ressaltar que a filariose pode ser controlada/combatida efetivamente por meio de ações preventivas simples, como: diminuição do contato homem-muriçoca, mediante a eliminação de focos de muriçoca peridomiciliares, uso de mosquiteiro; melhoria das condições ambientais, com a ampliação do serviço de esgotamento sanitário, cuidados com o destino do lixo; higiene pessoal dos portadores da doença, diminuindo, assim, a recorrência de crises de erisipela, que potencializam as chances de estabelecimento da elefantíase.

Adicionalmente, a filariose deveria ser merecedora de atenção especial em nosso Estado, tanto por se tratar de uma parasitose de notificação compulsória, cujo maior número de casos no país ocorre na Região Metropolitana do Recife (RMR), quanto por ser possível erradicá-la com a simples adoção de medidas preventivas. Portanto, ratifica-se a necessidade de um trabalho educativo urgente e contínuo nos bairros identificados como área de risco da doença.

A filariose é um problema presente em nosso Estado desde meados de 1918, com focos persistentes e em expansão na RMR (BRASIL, 2000). O seu crescente avanço em Pernambuco possivelmente está relacionado ao processo de urbanização, que vem se intensificando desde 1940. Nessa época, os trabalhadores agrícolas migravam para a capital em busca de melhores condições de vida e emprego, formavam assentamentos sem as menores condições de higiene, provocando um forte impacto na saúde da população urbana (ALBUQUERQUE, 1993). Na capital, os emigrantes ocuparam áreas de acesso difícil, sem rede elétrica, de água ou esgoto, provocando adensamento populacional em pequenas áreas com condições sanitárias precárias, favorecendo, assim, a permanência de focos antigos e o surgimento de outros.

Nesse contexto, a desigualdade social impera, o baixo poder aquisitivo favorece a ocupação crescente e desordenada de áreas de invasão e favelas, sem infra-estrutura sanitária, gerando condições para a ampliação no número de municípios atingidos pela filariose na RMR, que de três passaram a sete. Assim, além de Jaboatão dos Guararapes, Olinda e Recife,

\footnotetext{
${ }^{3}$ Conhecida no meio científico como filariose linfática, bancroftose ou elefantíase, sendo esta última denominação utilizada apenas para a fase crônica ou, ainda, mardita, denominação retirada dos questionários aplicados em estudo-piloto.
} 
foram incluídos Paulista, Abreu e Lima, Cabo de Santo Agostinho e Camaragibe (MEDEIROS et al., 1999). A edemicidade da filariose está relacionada diretamente a fatores como: pobreza, desinformação, deseducação, desorganização, favelização e ausência de esgotamento sanitário (BRASIL, 2000).

Segundo o Programa de Eliminação Global da Filariose, proposto pela Organização Mundial de Saúde, o combate/controle da doença passa pela tomada de ações práticas baseadas tanto na "interrupção da transmissão", como na "assistência aos portadores" (BRASIL, 2000, p. 12). Assim, para que a filariose se torne controlável em curto prazo e erradicável a médio e longo prazo, deve-se agir preventivamente com a melhoria nas condições sanitárias, eliminação de criadouros de muriçocas, identificação e tratamento dos parasitados, além de tratamento e atenção aos portadores de seqüelas. Para que essas ações se efetivem, assim como os cuidados e novos hábitos sejam incorporados ao cotidiano das pessoas que vivem em comunidades endêmicas, um vigoroso trabalho de educação em saúde é necessário, e deve ter seu início o mais cedo possível, já que a infecção pela Wuchereria bancrofti se instala na idade mais tenra do indivíduo: a infância. Conhecendo o que os indivíduos sabem, podemos criar meios para que ampliem seus saberes e ajam preventivamente contra a filariose, além da possibilidade de se tornarem agentes multiplicadores em suas famílias e comunidade.

\section{Educação em saúde: qual o papel da escola?}

Ao longo da história, a escola consolidou-se como transmissora do conhecimento científico, aquela que selecionaria os mais capacitados para seguir a carreira universitária e/ou obter títulos de prestígio, supervalorizando determinados conteúdos em relação a outros (ZABALA, 1998). Aos poucos, o contexto escolar foi se modificando no sentido de transformar a escola em um espaço aberto aos saberes de origem extra-escolar. A convivência entre os diferentes saberes enriquece a relação de ensino-aprendizagem, já que a escola passa a ser vista como uma instituição interligada a fatores sociais, políticos e econômicos, característicos da comunidade na qual está inserida. Segundo os Parâmetros Curriculares Nacionais (PCN's), ao se admitir que a realidade social é formada por diferentes classes e grupos dotados de valores e limites próprios, a escola passa a perceber que, isoladamente, não é capaz de mudar a sociedade, e que só por intermédio do estabelecimento de articulações com outros segmentos sociais pode superar o perfil de reprodução e assumir seu papel transformador (BRASIL, 1998).

Dentro dessa perspectiva, para que a escola supere tanto o tratamento meramente abstrato dos conteúdos, assim como a visão limitada de que sua aprendizagem apenas serviria para "passar de ano" (BRASIL, 1998, p. 24), é necessário que ela ofereça oportunidades aos alunos de perceberem os conteúdos como instrumentos de reflexão, estimulando-os a pensarem sobre que ações podem melhorar efetivamente sua qualidade de vida. Ao estimular os alunos a resolverem problemas e conflitos reais conjuntamente, e a falarem o que pensam, bem como valorizando suas experiências pessoais, a escola assume um trabalho pedagógico transformador, que passa a se refletir na qualidade de vida de seus alunos (BRASIL, 1998). É resgatando temas cotidianos que a escola flexibiliza o currículo e entra em sintonia com os interesses dos alunos, possibilitando, assim, a aproximação entre os saberes escolares e os extra-escolares. 
Por excelência, as problemáticas cotidianas são altamente complexas e dotadas de inúmeras variáveis que, para serem compreendidas em sua totalidade, necessitam do olhar das mais diversas áreas de conhecimento, sendo, portanto, transversais. De acordo com os PCN's, para que temas transversais sejam trabalhados, não é necessário "parar" a programação da disciplina, mas chamar tais temas para a sua metodologia e conteúdo. Dentre as questões apresentadas pelos temas transversais, a saúde se apresenta como temática de extrema importância na melhoria da qualidade de vida. Segundo os PCN's (BRASIL, 1998), a escola deveria assumir o papel social de instrumentalizar seus alunos para intervirem, individual e coletivamente, na manutenção da saúde, com base na formação de atitudes (como a cobrança de coleta regular de lixo, construção de rede saneamento básico) associadas a valores (como preservação do meio ambiente, qualidade de vida, vida saudável), construídas mediante um trabalho sistematizado e contínuo.

Dentro da perspectiva de um papel atuante das escolas na condução de uma melhor qualidade de vida, e sabendo da atual situação da RMR, onde 1,3\% da população está infectada pela filariose linfática bancroftiana, constituindo o $1^{\circ}$ lugar no ranking da estatística nacional (BRASIL, 2006), se estabelece uma premente necessidade de que as escolas da RMR se engajem nas ações de divulgação das informações sobre a doença, no intuito de preparar os indivíduos para se prevenirem do acometimento por filaríase. Sabendo do decisivo papel de mediador do professor na relação sujeito/objeto, destacado por Vygotsky (1993), o educador trabalharia integrado ao aluno, explicando, fornecendo informações, questionando e corrigindo os erros que, porventura, possam ocorrer durante o processo; e, até mesmo, antes disso, estimulando os alunos a explicarem com suas palavras o que sabem sobre determinado tema (MOYSÉS, 1995). As explicações dos alunos constituiriam o ponto de partida para o que se pretende ensinar. Assim, identificando-se o que os alunos sabem sobre sintomatologia, transmissão, tratamento e prevenção da filariose linfática, poder-se-ia desvendar quais as representações mentais construídas, os recursos (analogias, relatos de experiências vividas etc.) utilizados pelos alunos na construção de suas explicações sobre o dado fenômeno. Dessa forma, o professor passa a escolher de forma mais consciente qual(is) o(s) caminho(s) que seus alunos poderiam trilhar no sentido de aproximar o que eles já sabem (Domínio fonte) do que se apresenta como novo (Domínio alvo). Portanto, a abordagem dos modelos mentais, dentre tantas outras que buscam discutir a contribuição dos conhecimentos prévios na aquisição de novos saberes, não apenas elucidaria o que os aprendentes já sabem sobre a doença, mas informaria em que trecho do caminho (Domínio fonte '! Domínio alvo) eles se encontram.

Uma vez conhecendo os modelos explicativos dos alunos, a escola poderia otimizar o planejamento de suas estratégias pedagógicas, favorecendo grandemente o trabalho preventivo da filariose com base em ações como: (a) adoção de medidas de combate ao vetor (muriçoca); (b) valorização de hábitos simples de higiene, o que diminui consideravelmente a recorrência das crises de erisipela, reduzindo conseqüentemente o número de seqüelados (portadores de elefantíase), e (c) diminuição da resistência ao tratamento coletivo. Ao se conhecer o que os alunos sabem, é possível compreender melhor tanto suas dúvidas quanto suas opiniões sobre um determinado tema. Desse modo, poder-se-ia pensar em estratégias de ensino que privilegiassem atividades problematizadoras e que resgatassem a realidade dos alunos. Nesse sentido, o papel do ensino formal, aquele que acontece na escola, seria o de auxiliar na cons- 
Conhecendo alguns modelos mentais infantis...

trução de conhecimentos que os norteiem nos processos de escolha de hábitos de higiene e saúde, promotoras de melhores condições de vida.

Reconhecemos que não é necessária uma orientação formal da escola para que uma concepção seja construída, já que as crianças observam o meio ao seu redor e vão construindo idéias e explicações a fim de entender o que vêem. Tais construções estão impregnadas por sua cultura, pelas intervenções dos adultos e da infinidade de informações exibidas nos meios de comunicação (BESCHORNER e TERRAZZAN, 2004). São diversos os movimentos que tentam desvendar as concepções das crianças, e, em cada um deles, as concepções prévias dos sujeitos ganham nomenclaturas e enfoques diferentes (concepções alternativas/espontâneas; mudança conceitual (DINIZ, 1998); modelos mentais (MOREIRA, 2001) ou perfil conceitual (MORTIMER, 2000). Dentre as diferentes abordagens sobre o conhecimento prévio dos aprendentes e o seu papel na aprendizagem de conceitos científicos, focaremos a dos Modelos Mentais, por consistir não só em uma abordagem que permite desvelar as representações criadas pelos alunos, mas também por possibilitar ao professor a identificação dos recursos (analogias, resgate de experiências vividas etc.) utilizados por eles na estruturação de suas explicações e grau de compreensão sobre os mais diversos temas.

\section{Aquisição de conhecimento biológico segundo a abordagem dos modelos mentais}

Mesmo realizando experiências ou simplesmente observando o mundo que nos cerca, não podemos captá-lo diretamente. As pessoas apenas podem construir representações internas (mentais) desse mundo exterior (MOREIRA, 2001), assim, o que temos em mente não é o objeto, mas uma representação do que é o objeto. Tal representação apresenta dois aspectos importantes durante sua elaboração: um é o aspecto objetivo, como, por exemplo, a identificação de forma, cores, a possibilidade de aferição de tamanho, volume, altura, ou seja, tudo aquilo que o objeto por si só oferece de imediato; outro é o aspecto subjetivo, que depende de conceitos preestabelecidos e que foram adquiridos por meio de experiências com outros objetos semelhantes em outras situações. Algo que ilustraria ambos os aspectos da representação mental seria a análise de um quadro em uma sala de visitas. O que ele nos ofereceria de imediato, objetivamente? Teríamos uma noção precisa de: sua forma (se retangular, se quadrada etc.), as cores utilizadas, o tipo de tinta, o que retrata (se paisagem, se figuras humanas, se natureza- morta). Mas, se perguntarmos: o que o pintor quis expressar? Qual o significado do que se vê? Teremos, então, interpretações muito particulares (subjetivas) que dependem da vivência do indivíduo com esse tipo de arte ou com alguma situação anterior que, simplesmente, o impeça de se sentir tocado pela imagem. A noção de que o que temos guardado em nossa mente é uma representação de objetos, eventos, sistemas ou processos presentes no mundo que nos cerca, consiste na base da abordagem dos Modelos Mentais.

A abordagem dos Modelos Mentais marcou a década de 1990, pois buscou não apenas identificar as idéias prévias dos sujeitos, mas entender como estas influenciavam a construção de explicações sobre os elementos do mundo. Seu eixo central está nas relações analógicas estabelecidas entre o Domínio-fonte - que consiste no conhecimento prévio do aluno, 
ou seja, as informações cotidianas colhidas da sua relação com o meio em que está inserido e o Domínio-alvo - que seria o conhecimento a ser aprendido, como, por exemplo, um evento ou um elemento do mundo com o qual nos relacionamos - sem que haja, necessariamente, uma instrução formal (CAVALCANTE, 1997). Para a construção dos modelos, os aprendentes utilizam imagens, analogias e metáforas para auxiliar a visualização e a compreensão de um domínio-alvo aparentemente inacessível, por sua complexidade e abstração, sendo nessa possibilidade de materialização do abstrato que reside o valor dos Modelos Mentais (GILBERT e BOULTER, 1998).

$\mathrm{Na}$ tentativa de simplificar e tornar acessível o domínio-alvo, durante a elaboração do modelo mental, o sujeito seleciona apenas as informações que julga essenciais e que coincidem com as que já possui; essas idéias comuns a ambos os domínios constituirão o núcleo do modelo. As características selecionadas devem atender às exigências necessárias à compreensão do conceito, o que determina a especificidade do modelo construído. Há evidências de que, comumente, o processo de estruturação de um modelo mental se dá em três etapas: $1^{a}$ Modelo inicial, que corresponde à construção anterior, que o sujeito facilmente domina, originado em fatos do seu cotidiano; $2^{\mathrm{a}}$ - Estado gerador de novo modelo, ocorre quando as concepções prévias (modelos iniciais ou domínio-fonte) não mais, por si só, podem explicar o novo fenômeno (objeto/evento, ou domínio-alvo). Ocorre, então, uma reestruturação das idéias na tentativa de ampliar o modelo inicial, por meio da construção de relações analógicas que aproximem o que se sabe do que se deseja aprender; $3^{\mathrm{a}}$ - Modelo gerado consiste no produto final. Mais amplo, portanto, mais complexo do que o modelo inicial (ALBUQUERQUE, 2000; CAVALCANTE, 1997). Todavia, é importante destacar que a construção de um novo modelo, via revisão ou reestruturação do modelo anterior, deve ser vista como um evento possível de acontecer, não como uma etapa automática e necessária.

O modelo mental é um construto intermediário entre um domínio-fonte e um domínio-alvo que se estabelece com base em analogias entre domínios. Como ilustração para o que estamos descrevendo, analisaremos o conceito de glicose. Para que o indivíduo representasse tal conceito, ele buscaria listar pontos semelhantes entre o alvo e o seu repertório conceitual, podendo associar à glicose a idéia cotidiana de combustível. Ambos, glicose e combustível, teriam, como núcleo comum, a idéia de fornecimento de energia. Esta, no primeiro caso, para a sobrevivência das células e, conseqüentemente, do organismo, e, no segundo caso, para a locomoção dos automóveis. Inclusive Buske et al. (2004) identificaram o estabelecimento dessas pontes analógicas em muitos livros didáticos. Devido a esse caráter intermediário entre as abstrações teóricas e as ações concretas do cotidiano, o modelo mental pode permear diferentes contextos, guiando investigações futuras, justificando resultados e facilitando sobremaneira a comunicação de idéias complexas (GILBERT e BOULTER, 1998). As analogias são um recurso da aprendizagem bastante útil durante a construção de um modelo mental, já que torna simples ou familiar o domínio que se tenta compreender. Segundo Limón e Carretero (2000), a utilização de analogias seria algo extremamente necessário à introdução de conceitos científicos ou à alteração das idéias prévias dos alunos, sendo uma forma de se estabelecer relações entre o conceito novo e o que já conhecemos. Para Freitas (2000), a analogia poderia ser entendida sob duas perspectivas: na primeira, a analogia referente a um objeto/evento seria construída pela comparação entre estruturas pertencentes a dois domínios distintos, e, na segunda, seria resultante da comparação entre dois modelos dentro do mesmo domínio. Para 
ilustrar a última perspectiva, o autor comenta que Darwin, durante a elaboração de sua Teoria da Seleção Natural com populações naturais, teria se baseado na seleção artificial com populações domésticas. Com isto ele estaria buscando similaridades entre modelos diferentes dentro de um mesmo domínio, o da Biologia.

No que tange à exploração de atributos semelhantes entre domínios diferentes, teríamos, como ilustração, os resultados de uma pesquisa realizada com crianças entre 4 e 10 anos, na qual foi solicitado às crianças que tentassem explicar o percurso que o alimento faz dentro do corpo. Diante das respostas, verificou-se que as crianças menores tendem a associar o corpo humano a um depósito vazio, que é preenchido gradualmente pelos alimentos. Para algumas delas, ao se ingerir o alimento ou ele cai nas pernas ou se desloca pelo corpo por meio de algum tipo de movimento que ele realize, como o andar ou o pular. Para se construir esta concepção, a criança faz analogia ao conceito de queda livre dos corpos (TEIXEIRA, 1999), algo diretamente observável em seu dia-a-dia, e tenta construir sua explicação evidenciando similitudes entre estruturas de domínios diferentes, o da Biologia (processo digestório) e o da Física (movimento de queda livre). Uma vez que o sujeito elabora mentalmente um modelo, ele torna-se capaz de representar sua compreensão do objeto/evento e transmitir sua idéia a outros. Se o modelo construído for uma simples representação do objeto/evento, na qual não se estabeleceu nenhum tipo de justificativa para a ocorrência do fenômeno, teremos, segundo Cavalcante (1997), um Modelo Mental Descritivo. Entretanto, se o modelo tenta explicar as relações de causa e efeito, função e forma, existentes em um dado objeto/evento, teremos um Modelo Mental Explanatório ou Relacional.

No entender de Albuquerque (2000), ao construir um modelo mental, o sujeito inevitavelmente lançará mão de elementos que são característicos desse processo, como: 1 - Utilização de Analogias, que ocupa o papel central na construção dos modelos mentais de acordo com Duit e Glynn (1996). Uma vez que o aprendente estabelece relações analógicas entre os elementos comuns do seu modelo inicial (domínio-fonte) e do modelo-alvo (domínio-alvo), o objeto/evento em estudo se torna mais inteligível, por ter, como ponto de partida, as informações que o sujeito já domina; 2 - Antecipação de resultados: é a partir desta característica que o modelo mental construído permite ao sujeito, por meio de inferências, construir hipóteses sobre como funciona um determinado fenômeno-alvo e predizer qual deverá ser o produto final obtido com base em seu funcionamento, sem que o sujeito, ao ser perguntado, tenha de realizar uma determinada ação para dar uma resposta, simplesmente usará a inferência para isto; 3 - Construção Espontânea: os modelos mentais são construídos com base em elementos presentes no cotidiano do sujeito, para explicar o fenômeno sem que haja necessariamente uma instrução escolar, embora esta possa até influir na complexidade do modelo, mas não o impede de ser construído.

Mesmo reconhecendo os modelos mentais como uma proposta teórica explicativa do processo de aquisição e organização do conhecimento, Moreira (2001) e Albuquerque (2000) alertam que, uma vez que se tratam de análogos estruturais do mundo exterior, eles não são fidedignos ao objeto, mas uma representação do que é o objeto. Por ter aspectos objetivo e subjetivo, dão margem ao toque pessoal e, dessa forma, fatores como a incompletude, a instabilidade e a imprecisão dos modelos mentais, imprimem a eles limitações que devem ser consideradas ao se buscar planejar estratégias que promovam sua construção. 
Motta, M. B.; Teixeira, F. M.

\section{O estudo}

Nossa pesquisa teve como objetivo geral mapear e descrever os modelos mentais sobre filariose linfática, apresentados pelos alunos das escolas de região endêmica na RMR. Buscamos identificar, especificamente, os níveis de explicitação dos aprendentes sobre sintomatologia, transmissão, tratamento e prevenção relativos à parasitose.

\section{Método}

Amostra: no estudo principal foram pesquisados cinqüenta alunos da $1^{a}$ série do $2^{\circ}$ ciclo ( $3^{a}$ série do fundamental I) de duas escolas públicas da rede municipal do Recife, localizadas em bairros de alta endemicidade de filariose: Alto de Santa Terezinha e Alto do Pascoal.

Procedimento: O estudo foi subdivido em duas etapas: 1-Estudo Piloto: foi realizado em escola da Rede Municipal de Olinda, localizada no bairro de Peixinhos, com 23 alunos do nível $\mathrm{V}$ (equivalente a $7^{\mathrm{a}}$ e $8^{\mathrm{a}}$ séries) de educação de jovens e adultos (EJA), com faixa etária variando entre 15 e 35 anos, e residentes em bairros próximos à escola. Aplicamos questionário com perguntas abertas (RICHARDSON, 1999), com o objetivo de testar e ajustar o roteiro da entrevista a ser aplicada na segunda fase; 2-Estudo Principal: foi realizado nas escolas de áreas endêmicas, por meio de entrevista individual, sempre iniciada por intermédio da apresentação de fotografia de pessoas acometidas pela elefantíase, com o objetivo de identificarmos: (a) se há familiaridade da criança com a fase crônica da filariose e (b) quais os modelos mentais das crianças sobre o processo de adoecimento visto na figura, no que se refere à sintomatologia, à transmissão, ao fator causal, ao tratamento e a medidas preventivas (MOTTA, 2004).

\section{Análise e discussão dos resultados}

Ao término das entrevistas, transcrevemos as mesmas e lemos cada protocolo na íntegra, buscando relacionar os dados obtidos com os eixos temáticos previamente estabelecidos, como: sintomatologia, transmissão, fator causal, tratamento e prevenção. Baseados no modelo de análise categorial temática de Bardin (1977), organizamos os dados por meio do desmembramento dos textos presentes nos protocolos em unidades menores, as quais foram reagrupadas mediante semelhanças, o que se repetiu dentro de cada eixo temático proposto. A análise e discussão que se seguem referem-se aos dados obtidos no estudo principal.

Processo de adoecimento: Tentamos explorar como as crianças descrevem o que acontece durante o período em que a doença se instala no organismo, tomando, como referência, a seqüência de adoecimento, criada com base na bibliografia consultada (DREYER e NORÕES, 1997): Fonte de contaminação $\rightarrow$ ! Agente causal $\rightarrow$ ! Atuação do patógeno ${ }^{4} \rightarrow$ ! Aspecto de inchaço. Identificamos que cerca de $68 \%$ das crianças tentavam, de alguma forma, descrever o processo, enquanto $32 \%$ não conseguiram.

Dentre as explicações construídas pelas crianças, dois modelos tiveram maior desta-

${ }^{4}$ Agente causador da doença. 
Conhecendo alguns modelos mentais infantis...

que. No Modelo 1, o inchaço ocorreria sem que houvesse uma atuação efetiva do patógeno: "Ela (filariose) pica, e bota os negócios (bactéria) [...] dentro [...] Incha logo." (G. B. da S.); No Modelo 2, o inchaço ocorreria pela ação intencional do patógeno, modificando, assim, a dinâmica e/ou a estrutura interna do organismo: "Vai fazendo bolinha (o veneno) e cresce e vai ficando inchada (a perna).” (W. R. A.).

Observamos que as crianças, na tentativa de ajustarem suas idéias à questão apresentada, apoiavam seus modelos fortemente em dois tipos de analogias. No primeiro, teríamos a analogia entre modelos diferentes de um mesmo domínio, o da biologia (FREITAS, 2000), como em: "Mas é uma carne como, aquela que tem dentro do osso da galinha [...]". Nesse exemplo, a criança compara o modelo anatômico humano ao de uma ave. No segundo modelo, a analogia ocorre entre domínios diferentes (FREITAS, 2000), como em: "A gente vai andando, aí vai descendo a carne todinha pelo pé, aí fica duro, duro". Temos, portanto, a utilização tanto do domínio biológico, quando a criança faz referência ao aumento do volume tecidual, como do domínio físico, quando resgata o conceito de queda livre dos corpos.

Formas de identificação: Buscamos saber qual(is) forma(s) é(são) apontada(s) pelos aprendentes como reveladora(s) de positividade da doença. Obtivemos que, para 52\% das crianças, o aspecto de inchaço é a forma mais comum de identificação da doença, e verificamos que dois modelos foram bastante recorrentes. No Modelo 1, a identificação se deu pela presença de inchaço (isolado ou associado à realização de exame), como no exemplo a seguir: "Só sabe quando ela (perna) incha. Aí vai no médico, aí o médico faz o exame e diz que ela tá com a doença." (M. J. V. S.). Durante a construção desse modelo, as crianças priorizam a mera descrição do que observam de imediato, os atributos externos, permitindo sua classificação como: Modelos Mentais Descritivos (CAVALCANTE, 1997). No Modelo 2, a identificação se dá exclusivamente pela realização de exame, como podemos ver no trecho a seguir: "Eu acho que ele (o médico) bota um [...] negócio como quando a pessoa tá grávida (passa a mão na barriga), aí ele (o médico) bota na perna pra ver se tá [...] doente. [...] Eu acho que ele (o médico) ver um germinho andando [...]” (M. A. da S.). Nesse modelo, os alunos tentam justificar a necessidade de se realizar o exame como forma de detectar o elemento (vivo ou não-vivo) que promove a doença, o que nos permite a classificação de tais representações como: Modelos Mentais Explanatórios (CAVALCANTE, 1997).

Sintomatologia: Mesmo a filariose apresentando grande variedade de sintomas, devido a fatores como o nível de resposta imunológica do indivíduo e o estágio larval do verme (DREYER e NORÕES, 1997), buscamos identificar quais sintomas são atribuídos aos doentes, pelas crianças. Verificamos que, para 50\% delas, uma pessoa só é considerada doente a partir da manifestação do inchaço em um de seus membros, enquanto, para 18\%, a sintomatologia é difusa, e 4\% acreditam que os sintomas locais são acompanhados de mal-estar geral. Para 4\%, os sintomas são decorrentes dos efeitos colaterais da medicação distribuída nas campanhas de saúde, os outros $24 \%$ ou não atribuem sintomatologia alguma ou nem quiseram responder a questão. Merecem destaque dois modelos explicativos: O Modelo 1, no qual as crianças limitam a sintomatologia a alterações físicas, como em "[...] Dor na perna ou no braço, onde tem canto que incha.” (R. D. da S.); O Modelo 2 descreve uma sintomatologia que vai além das alterações físicas afetando o campo psicológico, como em "[...] Fica triste e fica com a perna doendo [...]” (A. S. dos S.).

Nos modelos apresentados, não identificamos relações analógicas, mas uma forte tendência das crianças de apoiarem suas explicações em observações diretas, buscando ele- 
mentos cotidianos tanto em aspectos orgânicos (febre, dor) como nos aspectos psicológicos (tristeza, sensação de morte eminente), possivelmente relatados por parentes, vizinhos ou amigos próximos à família.

Medidas para o combate/controle da Filariose (prevenção): Segundo Rey (2001), tais medidas estão divididas em dois blocos: 1. Métodos Curativos (individual ou coletivo) por meio de quimioterápicos; 2. Métodos Preventivos, que compreendem desde a redução do contato homem-muriçoca até a tentativa de garantir saneamento ambiental adequado. Observamos que estas medidas, quando identificadas pelas crianças, não são percebidas como complementares, as representações se limitam à adoção de uma ou outra medida preventiva. Dentre as citadas, as mais lembradas foram uso de medicamento (24\%), diminuição do contato com o transmissor (14\%), e melhoria das condições ambientais (8\%).

Tratamento: Mediante uma investigação mais aprofundada dessa temática, pudemos perceber em que medida as crianças acreditam na existência de tratamento para a filariose, assim como qual momento seria o mais adequado ao seu início, e, por fim, determinar o nível de eficácia atribuído ao tratamento apontado. Verificamos que, para 78\% das crianças, existe tratamento, e que seu cumprimento é decisivo para a cura da doença. No que se refere às possíveis formas de tratamento, surgiram dois modelos mentais: Modelo 1, o tratamento é estritamente local; Modelo 2, o tratamento tem efeito sistêmico, como podemos ver a seguir: "[...] Num tem o ferro (substância supostamente presente na água que é injetada no sujeito pela muriçoca) dela? O ferro dela (da muriçoca) está fraco. Tá forte fora, mas quando o mosquito pica [...] o remédio já tá lá dentro, né? [...] Ele pica, ai quando chega lá dentro [...] a água fica fraquinha, num entra na temperatura que quer." A criança entende que, uma vez tomado o medicamento, este se dissemina pelo corpo e protege o sujeito contra a invasão do agente causal. Sobre o momento para o início do tratamento, identificamos dois modelos: Modelo 1, o tratamento tem início em período específico, ou antes ou depois do aparecimento do inchaço. Este modelo permeou o discurso de $60 \%$ das crianças; o Modelo 2, construído por 40\% dos entrevistados, indica que o tratamento pode ser feito em qualquer fase da doença. Por fim, no que tange à eficácia do tratamento, cerca de $80 \%$ das crianças acreditam na cura e redução parcial ou total das seqüelas.

\section{Considerações finais}

Investigamos os modelos mentais sobre filariose linfática criados pelas crianças residentes em área endêmica, buscando contribuir com informações que possam subsidiar: 1- o planejamento das práticas pedagógicas mais coerentes com a realidade desses alunos; 2- as decisões sobre o modo mais adequado para a divulgação do conhecimento sobre a filariose linfática nas campanhas de saúde promovidas em nosso Estado.

Verificamos que, para a maioria das crianças, a filariose pode ser evitada, tem tratamento e sua origem estaria em algum fator externo ao seu corpo. Ao tentarem descrever os sintomas e o processo de adoecimento, as crianças apresentam grande dificuldade, possivelmente pela tendência em apoiarem seus modelos em atributos externos. No que se refere à construção dos modelos mentais, as crianças utilizam, freqüentemente, analogias, demonstrando ser um recurso que já faz parte do repertório explicativo delas; há também uma forte influência das observações e experiências vivenciadas pelas crianças em sua comunidade. As- 
sim, o fato de as crianças poderem explicar e compreender as experiências vividas, seria forte indicativo de que trazer situações reais para dentro da escola consiste em metodologia de ensino bastante adequada a temas transversais, como a filariose. Por exemplo: levantamentos do número de casos registrados na comunidade, entrevistas com pessoas acometidas do agravo, identificação das condições ambientais do bairro para proliferação da muriçoca, entre outras possibilidades.

No que diz respeito às formas de identificação da doença, são mais lembrados o inchaço e os efeitos colaterais provocados pelo uso de medicamentos pelos doentes, o que sugere que há a crença de que uma pessoa só é considerada doente quando se encontra na fase crônica ou quando sente algum desconforto produzido pelo uso de medicamento distribuído possivelmente nas campanhas da Secretaria de Saúde (2002). Dessa forma, consolidar-se-ia o descaso com os pequenos sinais presentes na fase inicial da doença, sendo mais um fator que retardaria a busca pelo serviço de saúde.

A transmissão da filariose é atribuída à muriçoca/mosquito, por $42 \%$ dos alunos. Constatamos que a medida preventiva "uso de medicamento" foi citada por $24 \%$ das crianças, sendo também lembrada como forma de tratamento da doença em ambas as escolas. Vale ressaltar que, mesmo com campanhas de saúde como a Xô Filariose, que dão destaque à prevenção da doença por meio dos cuidados com o ambiente, estes foram pouco lembrados pelas crianças.

Em relação ao tratamento, é importante destacarmos que a grande maioria dos aprendentes acredita que o tratamento é possível e que o cumprimento das recomendações médicas, que para eles se limitam a "tomar o remédio", é fundamental para o sucesso do tratamento, sendo os métodos alternativos raramente citados.

Diante da reconhecida influência do repertório prévio na estruturação de modelos explicativos, destacamos a necessidade de se fazer uma avaliação cuidadosa das representações infantis descritas nesta pesquisa, tanto por parte dos educadores como, também, pelos responsáveis por campanhas de saúde no Estado e nos municípios.

Entretanto, para que a prática pedagógica dê condições aos alunos de ampliarem suas idéias sobre filariose, fazendo-os adotar os cuidados necessários ao controle efetivo da doença e de suas seqüelas, não basta ao educador conhecer os modelos de seus alunos, mas ele deve ter um nível de conhecimento que permita não só estar ciente dos modelos como, também, desenvolver atividades que ampliem o saber dos alunos e os estimulem a agir de modo preventivo.

Sugerimos que sejam promovidos, na escola, encontros entre os professores e agentes de saúde, com o objetivo de possibilitar aos docentes a apropriação de conceitos importantes, para um melhor entendimento sobre a doença, dando a estes a preparação básica que os ajudará no suporte das campanhas para o combate à transmissão da filariose e a redução de seqüelas nos doentes, promovidas pela escola. Uma vez estabelecido um canal de comunicação entre educação e saúde, cria-se a oportunidade única de se estabelecer um padrão de comportamento preventivo, fruto da compreensão de que só com base em um trabalho coletivo árduo e permanente, pode-se pensar na erradicação da filariose e dos muitos outros agravos presentes no dia-a-dia de sua comunidade.

Por fim, sugerimos que, em futuras pesquisas, sejam idealizadas e avaliadas propostas para práticas pedagógicas inovadoras que considerem os modelos construídos pelas crianças sobre a filariose linfática. 
Motta, M. B.; Teixeira, F. M.

\section{Referências}

ALBUQUERQUE, M. F. P. M. Urbanização, favelas e endemias: a produção da filariose no Recife, Brasil. Cadernos de Saúde Pública, Rio de Janeiro, v. 9, n. 4, p. 487-497, 1993.

ALBUQUERQUE, T. C. C. Modelos mentais infantis sobre a respiração e o sistema respiratório. 2000. 106f. Dissertação (Mestrado em Psicologia Cognitiva) - Centro de Filosofia e Ciências Humanas, Universidade Federal de Pernambuco, Recife, 2000.

BARDIN, L. Análise de conteúdo. Lisboa: Edições 70, 1977.

BESCHORNER, E.; TERRAZZAN, E. Sala de aula, que lugar é este? Disponível em: $<$ http://www.educacaoonline.pro.br/sala_de_aula_que_lugar.asp.> Acesso em: 05 ago. 2004.

BRASIL. MINISTÉRIO DA EDUCAÇÃO E DO DESPORTO. Brasil. Parâmetros Curriculares Nacionais - Temas Transversais. Ensino de $5^{a}$ a $8^{a}$ séries. Brasília: Secretaria de Ensino Fundamental, 1998.

MINISTÉRIO DA SAÚDE. Brasil. Gerência Técnica do Programa de Eliminação da Filariose. Síntese Epidemiológica da Filariose- 2006. Disponível em <http:/ / portal.saude.gov.br/portal/arquivos/pdf/filariose.pdf > . Acesso em: 01 jan. 2007.

. Fundação Nacional de Saúde. Relatório da reunião de Avaliação do Programa

de Controle da Filariose Linfática, referente ao Plano de Eliminação da Filariose Linfática no Brasil, Recife-PE, 2000. Brasília, 2000.

BUSKE, R. et al. Analogias como recurso didático: mesmos análogos diferentes alvos. In: ENCONTRO PERSPECTIVAS DO ENSINO DE BIOLOGIA, 9., 2004, São Paulo. Anais... São Paulo: Universidade de São Paulo, 2004. p. 169-170.

CAVALCANTE, P. S. A study of the interaction of teachers's ideas of childrens learning in science and the impact of such interaction. 1997. 349f. Tese (Doutorado) Universidade de Newcastle upon Tyne, UK, 1997.

DINIZ, R. E. S. Concepções e práticas pedagógicas do professor de ciências. In: NARDI, R. (Org.). Questões atuais do ensino de Ciências. São Paulo: Escrituras, 1998. p. 27-32.

DREYER, G.; NORÕES, J. Filariose bancroftiana. In: LUCENA, V. G. et al. Condutas em Clínica Médica. Recife: Serviço de Clínica Médica do Hospital das Clínicas/Universidade de Pernambuco, 1997. p. 399-421. 
Conhecendo alguns modelos mentais infantis...

DUIT, R.; GLYNN, S. Mental modelling. In: WELFORD, G.; OSBORNE, J.; SCOT'T, P. (Eds.) Research Science Education in Europe: current issues and themes. London: Falmer Press, 1996. p. 166-76.

FREITAS, S. D. Analogias e metáforas no ensino de ciências: Que dizem as pesquisas? In: ENCONTRO "PERSPECTIVAS DO ENSINO DE BIOLOGIA"/SIMPÓSIO LATINOAMERICANO DA IOESTE (INTERNATIONAL ORGANIZATION FOR SCIENCE AND TECHNOLOGY EDUCATION), 7., 2000, São Paulo. Anais... São Paulo: Universidade de São Paulo, 2000. p. 281-285.

GILBERT, J. K.; BOULTER, C. J. Aprendendo ciências através de modelos e modelagens. In: COLINVAUX, D. Modelos e educação em Ciências. Rio de Janeiro: Ravil, 1998. p. 12-34.

LIMÓN, M.; CARRETERO, M. Las ideas previas de los alumnos. ¿Qué aporta este enfoque a la enseñansa de las ciencias? In: CARRETERO, M. et al. Construir y enseñar las Ciências Experimentales. Buenos Aires: Impreciones Sud América, 2000. p. 19-43.

MEDEIROS, Z. et al. Screening of army soldiers for Wuchereria bancrofti infection in the metroplitan Recife region, Brazil: implications for epidemiological surveillance. Tropical Medicine and International Health, Oxford, v. 4, n. 7, p. 499-505, 1999.

MOREIRA, A. M. Modelos mentais. In: MORTIMER, E. F. (Org.). Linguagem, cultura e cognição: reflexões para o ensino e a sala de aula. Belo Horizonte: Autêntica, 2001. p. 189220 .

MORTIMER, E. F. Linguagem e formação de conceitos no ensino de ciências. Belo Horizonte: Editora UFMG, 2000.

MOT'TA, M. B. Modelos mentais sobre Filariose Linfática em alunos das escolas de áreas endêmicas na região metropolitana do Recife. 2004. 168f. Dissertação (Mestrado em Educação) - Centro de Educação, Universidade Federal de Pernambuco, Recife, 2004.

MOYSÉS, L. O desafio de saber ensinar. 2. ed. Campinas/Rio de Janeiro: Papirus/ Editora da Universidade Federal Fluminense, 1995. p. 21-29.

REY, L. Parasitologia: parasitos e doenças parasitárias do homem nas Américas e na África. 3. ed. Rio de Janeiro: Guanabara Koogan, 2001. p. 636-638.

RICHARDSON, R. J. (Org.). Pesquisa social: métodos e técnicas. 3. ed. São Paulo: Atlas, 1999.

SECRETARIA DE SAÚDE. Pernambuco. Subprograma de controle da Filariose Linfática. In: _. Programa de Saúde Ambiental. Recife, 2002. 
Motta, M. B.; Teixeira, F. M.

TEIXEIRA, F. M. Conhecimento biológico das crianças: um domínio autônomo? Concepções sobre o aparelho digestivo. Psicologia: Teoria e Pesquisa, Brasília, v. 15, n. 1, p. 1-8, 1999.

VYGOTSKY, L. S. Pensamento e linguagem. São Paulo: Martins Fontes, 1993.

ZABALA, A. A prática educativa: como ensinar. Trad. Ernani F. da F. Rosa. Porto Alegre: Artmed, 1998.

Artigo recebido em dezembro de 2006 e aceito em julho de 2007. 